\title{
International Journal of

\section{Effect of plyometrics exercises on cardio-vascular capacity and playing ability of cricket players}

\section{ABHAY N. BUCHHA}

Received : 22.07.2014; Revised : 01.09.2014; Accepted : 15.09.2014

Author for correspondence :

ABHAY N. BUCHHA

Shri. Shivaji College of Physical

Education, AMRAVATI (M.S.) INDIA

\section{- ABSTRACT}

Plyometrics (also known as "plyos") is a type of exercise training designed to produce fast, powerful movements, and improve the functions of the nervous system, generally for the purpose of improving performance in sports. Plyometrics has been shown across the literature to be beneficial to a variety of athletes. Benefits range from injury prevention, power development and sprint performance amongst others. Plyometric exercise involves and uses practicing plyometric movements to enhance tissues abilities and train nerve cells to stimulate a specific pattern of (muscle contraction) so the muscle generates as strong a contraction as possible in the shortest amount of time. Low-intensity variations of plyometrics are frequently utilized in various stages of injury rehabilitation, indicating that the application of proper technique and appropriate safety precautions can make plyometrics safe and effective for most people. Plyometric exercises involve an increased risk of injury due to the large forces generated during training and performance, and should only be performed by well-conditioned individuals who are under supervision. The purpose was to determine the effect of Plyometrics exercises on cardio-vascular capacity and playing ability of inter-collegiate cricket players of Sant Gadge Baba Amravati University, Amravati. The study was delimited to 30 male inter-collegiate players in the age ranging from 18 to 28 years. The players were divided into two equal groups (i.e. experimental and control group) on the basis of the mean performance of pre-test score. Two tests were performed on the subjects i.e. coopers 12 minute run and walk and three Judges playing ability test. To determine the significant difference t-test was employed and level of significance was set at 0.05 level of confidence. After analysis of data it has been concluded that, there was no significant difference found in vascular endurance and cricket playing ability control group. The significant effect observed in experimental group on cardio-vascular endurance and cricket playing ability, because of training schedule of players. In the post test of control and experimental group significant difference found in cardio-vascular endurance, Off side batting ability, Defend batting ability, Length bowling ability, Full length bowling ability and Overall playing ability. But insignificant in fielding ability.

- Key Words : Plyometric, Endurance, Playing ability

- How to cite this paper : Buchha, Abhay N. (2014). Effect of plyometrics exercises on cardio-vascular capacity and playing ability of cricket players. Internat. J. Phy. Edu., 7 (2) : 45-49. 